\title{
Classification of the Foot Movements with Inertial Measurement Sensor for
}

\author{
Ankle-Foot Prosthesis
}

\author{
Selin AYDIN FANDAKLI ${ }^{1 *}$, Halil Ibrahim OKUMUS ${ }^{2}$
}

\begin{abstract}
Today, Inertial Measurement Units is used for control in lower extremity prosthesis studies. In this article, an application related to the analysis and classification of foot movements such as dorsiflexion, plantarflexion, inversion and eversion is presented. This study aims to perform the classification of foot movements to recognize the movement pattern and to adapt to abnormal walking conditions for the robotic foot system. Nine parameters are measured with motion data from the IMU sensor connected to the metatarsal of the foot from eleven volunteers aged 20-34 years. Size is reduced by extracting statistical properties such as sum, mean, standard deviation, covariance, skewness and kurtosis from these parameters. Classification process is performed with classifiers such as Decision Tree, Linear Discriminant Analysis, Naïve Bayes Classifier, K-Nearest Neighbor and Support Vector Machine separately for each person. The classification accuracies obtained for 11 volunteers are averaged and the highest accuracy is obtained with 97.2\% for KNN.
\end{abstract}

Keywords: prosthesis, gyroscope, support vector machine, k-nearest neighbor, accelerometer, magnetometer

\section{Ataletsel Ölçüm Sensörü ile Ayak Protezi için Ayak Hareketlerinin Sinıflandırılması}

\section{$\ddot{O} \mathbf{z}$}

Günümüzde Atalet Ölçüm Birimleri alt ekstremite protez çalışmalarında kontrol amaçlı kullanılmaktadır. Bu yazıda dorsifleksiyon, plantarfleksiyon, inversiyon ve eversiyon gibi ayak hareketlerinin analizi ve sınıflandırılması ile ilgili bir uygulama sunulmuştur. Bu çalışma, robotik ayak sistemi için hareket modelini tanımak ve anormal yürüme koşullarına uyum sağlamak için ayak hareketlerinin sınıflandırılmasını amaçlamaktadır. 20-34 yaşları arasındaki on bir gönüllünün ayağının metatarsalına bağlı IMU sensöründen gelen hareket verileriyle dokuz parametre ölçülür. Bu parametrelerden toplam, ortalama, standart sapma, kovaryans, çarpıklık ve basıklık gibi istatistiksel özellikler çıkartılarak boyut küçültülür. Karar Ağacı, Doğrusal Ayrım Analizi, Naïve Bayes Sınıflandırıcı, K-En Yakın Komşu ve Destek Vektör Makinesi gibi sınıflandırıcılar ile her kişi için ayrı ayrı sınıflandırma işlemi yapılır. 11 gönüllü için elde edilen sınıflandırma doğruluklarının ortalaması alınmış ve en yüksek doğruluk KNN için \% 97.2 ile elde edilmiştir.

Anahtar Kelimeler: protez, jiroskop, destek vektör makinesi, k-en yakın komşu, ivmeölçer, manyetometre.

\footnotetext{
${ }^{1}$ Karadeniz Technical University, Department of Electrical and Electronics Engineering, Trabzon, Turkey, selinaydin@ktu.edu.tr ${ }^{2}$ Karadeniz Technical University, Department of Electrical and Electronics Engineering, Trabzon, Turkey, okumus@ktu.edu.tr 


\section{Introduction}

Surgical cutting of any body part from the body is called amputation, while the person who has undergone amputation is called amputee. Prostheses are artificial devices used by amputees who suffer congenital or subsequent limb loss due to illness and trauma, instead of missing body parts. In the United States, a total of 185000 amputations are performed each year on the lower and upper extremities. $85 \%$ of all amputations are in the lower extremities. According to the study, the number of people with limb loss is 1.6 million in 2005, and it is estimated that it will increase to 3.6 million in 2050 (Ziegler-Graham, 2008). In a study involving all inpatient cases with lower extremity amputation from 2005 to 2015, there were 55595 people with lower extremity amputation detected in Germany in 2015. This rate is quite high compared to other European countries (Spoden et al., 2019). One of the most important causes of all lower extremity amputations is peripheral arterial disease, which occurs when blood flow to the limbs is restricted (McDermott et al., 2001). It is estimated to occur in one in five people over the age of 60 in the UK, according to the study in (Meffen et al., 2020). The amputation rate in these patients is thought to be $3 \%-4 \%$ (Steffen etal., 2008).

In the study, Gao et al. uses Inertial Measurement Unit (IMU) to recognize locomotion modes such as level-ground walking, up slope, down slope, stair descent and stair ascent for three healthy and three below-knee amputees. The data transferred to the computer with the IMU is then used for offline processing. As a result, an average accuracy of $98.5 \%$ is achieved in these five locomotion modes (Gao et al., 2020).

Jiang et al. conduct a preliminary study to determine the ankle position of 3 healthy volunteers using force myography (FMG) signals. In this study, they obtain an average prediction accuracy of $94 \%$ with the cross-validation evaluation with the LDA classifier and $85 \%$ with the cross-trial evaluation (Jiang et al., 2016).

Quraishi et al. perform electromyography-based control of foot movements such as dorsiflexion, plantarflexion, adduction, and abduction with 15 male and 5 female volunteers. For this, three classifiers, LDA, KNN and naive bayes, are used. These classifiers are evaluated in terms of both logarithmic transferred time-domain features (LTD) and traditional time-domain features (TTD). The highest performance is achieved with an average classification accuracy of $97.23 \%$ using the LDA classifier and LTD (Quraishi et. al., 2016).

In the study, joint angle calculation method based on IMUs is used to perform human motion analysis with nonlinear least squares techniques (Seel, 2014). In a study involving 17 transtibial amputees, 16 transfemoral amputees, and 14 healthy controls, acceleration and angular velocity data are collected during ground walking using an IMU sensor with 3-axis accelerometer and a 3-axis 
gyroscope. The collected data are analyzed using 3 different algorithms, and as a result they show that the IMU step demarcation algorithms provide more consistent step demarcation (Fleck et al., 2018).

Parkka and his team examine the classification of daily physical activities such as walking, running, and cycling using wearable sensors in their study with 16 subjects. They use custom decision tree, automatically generated decision tree and artificial neural network as classifiers and achieve a total classification accuracy of $82 \%, 86 \%$, and $82 \%$, respectively. The results show that many daily activities can be recognized with good accuracy using sensors (Parkka et al., 2006).

Li et al. propose an adaptive and online algorithm based on a triple Markov model using a single IMU sensor to detect movement activities such as walking, running, stair ascent and stair descent. They have clearly demonstrated that this method performs well with the help of IMU sensors, achieving an accuracy rate of up to $99.2 \%$ with the proposed algorithm ( $\mathrm{Li}$ et al., 2019).

In this study, the raw data obtained from IMU sensor from the foot of 11 volunteers are classified extracting features with Decision Trees, Naïve Bayes, Linear Discriminant Analysis (LDA), K-Nearest Neighbor (KNN) and Support Vector Machine (SVM). According to the classification accuracy, the results are compared and $\mathrm{KNN}$ is obtained as the most suitable classifier for human movement classification.

\section{Materials and Methods}

Gait analysis data obtain at the Mechanical Engineering Biomechanics Laboratory of the Middle East Technical University, using the Inemo inertia module LSM9DS1 working on an NRF52 containing 9 degrees of freedom, triaxial gyroscope, triaxial accelerometer and triaxial magnetometer, as seen in Figure 1.

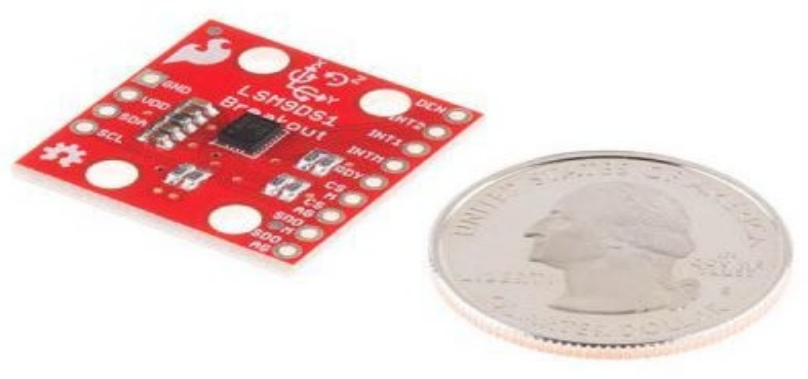

Figure 1. 9 degrees of freedom IMU-LSM9DS1

Figure 2 shows the axis direction of the LSM9DS1 and Table 1 shows the measuring range of the sensors. 

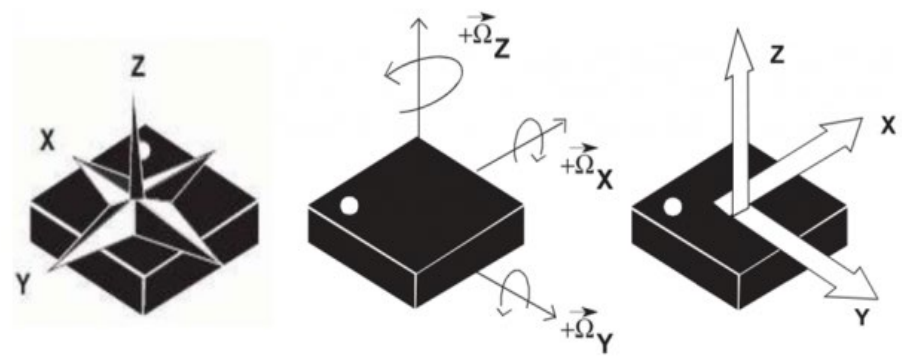

Figure 2. Axis orientations of LSM9DS1

Table 1. Measuring Range of LSM9DS1

\begin{tabular}{ccc}
\hline Linear Acceleration & Gauss Magnetic & Dps Angular Rate \\
\hline $\pm 2 / \pm 4 / \pm 8 / \pm 16 \mathrm{~g}$ & $\pm 4 / \pm 8 / \pm 12 / \pm 16$ & $\pm 245 / \pm 500 / \pm 2000$ \\
\hline
\end{tabular}

Gyroscope is a sensor that measures angular velocities in degrees/second. Filters are used to prevent angles from shifting, which calculates angular velocity even in a stationary object. The magnetic field from the magnetometer is used to obtain the yaw orientation angle (Yuliani and Saputra, 2016).

The sensor graph obtained by the analysis of the dorsiflexion, plantarflexion, inversion and eversion movements of the subject 1 is given in Figures 3, 4, 5 and 6, respectively.
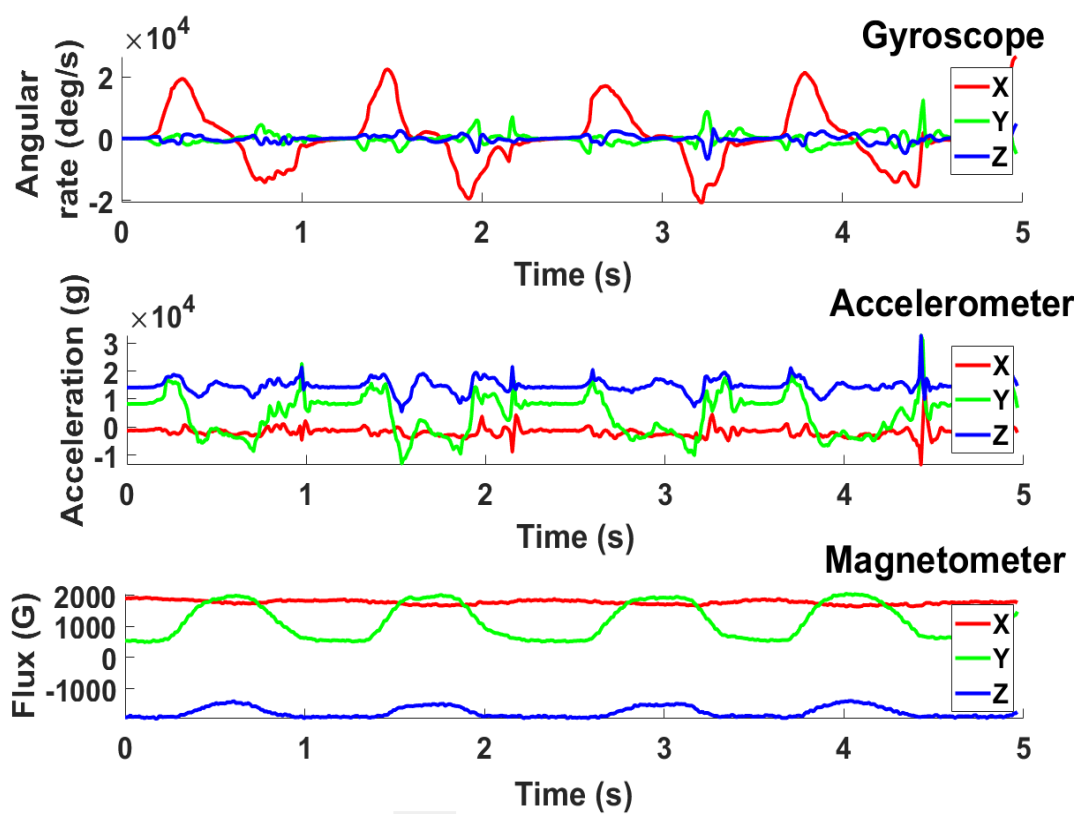

Figure 3. Sensor raw data obtained as a result of dorsiflexion movement of subject 1 

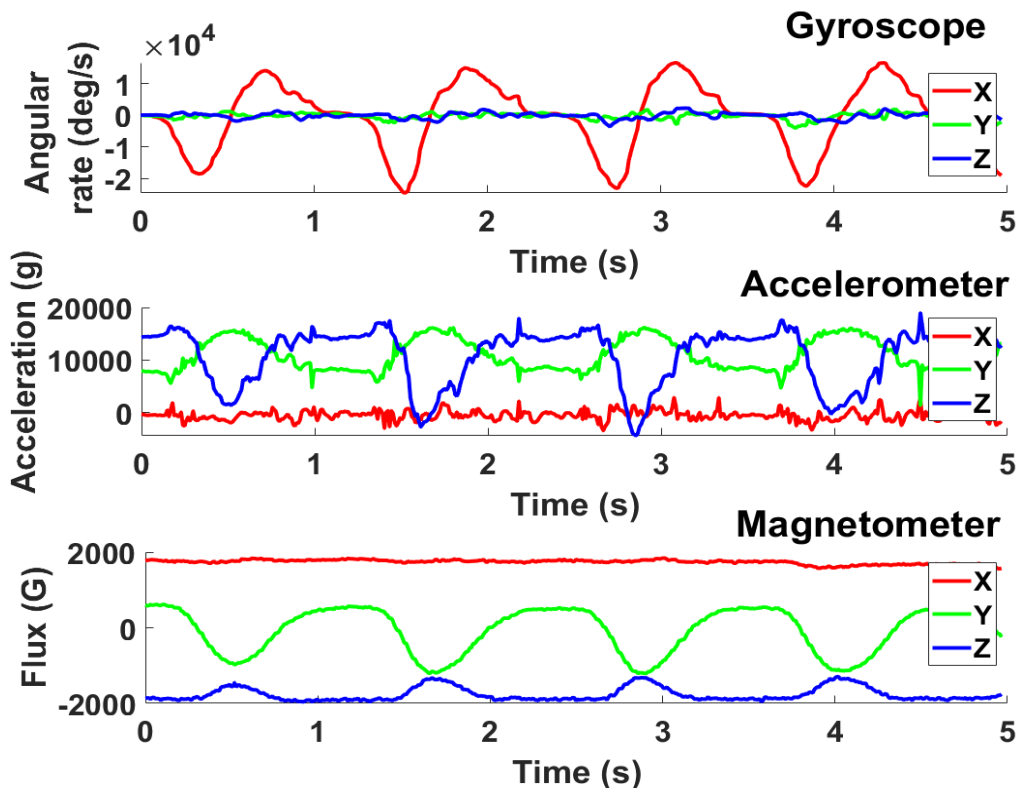

Figure 4. Sensor raw data obtained as a result of plantarflexion movement of subject 1
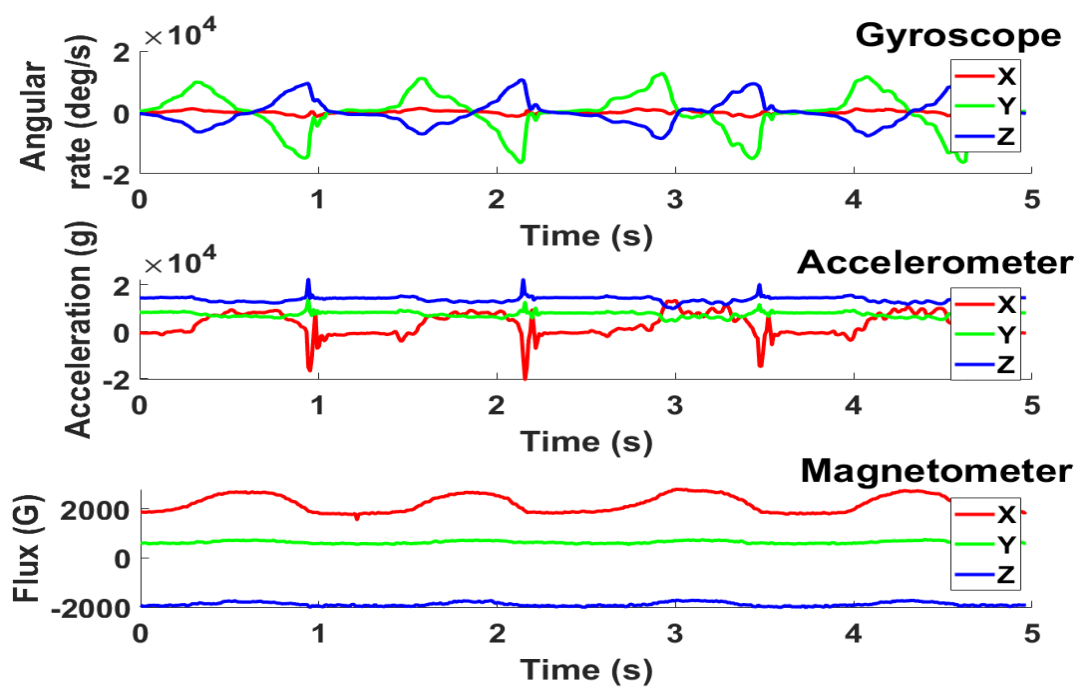

Figure 5. Sensor raw data obtained as a result of inversion movement of subject 1
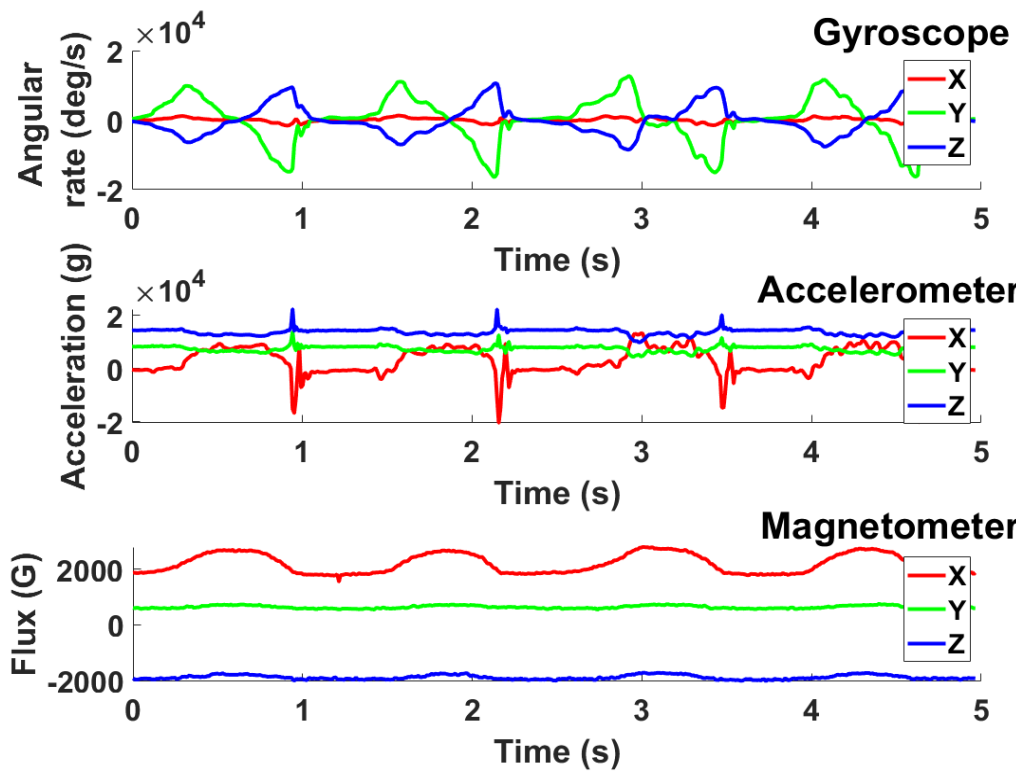

Figure 6. Sensor raw data obtained as a result of eversion movement of subject 1 


\subsection{Data Set Description}

Eleven healthy subjects, consisting of 8 men and 3 women, complete each of the Dorsiflexion, Plantarflexion, Inversion and Eversion movements by performing 50 trials at their own pace on the force plate. Data are acquired using four inertial sensors connected to the right and left leg (lower lateral leg) and right and left metatarsals (foot) and transferred to the PC with the USB-6212 Multifunction I / O Device from National Instruments are analyzed offline using MATLAB. Raw data are sampled at $100 \mathrm{~Hz}$. The hardware specifications of the computer used in the experimental studies are as follows: Windows 10 Pro, Intel ® Core TM i7-4500U CPU @ 1.80 GHz 2.40 GHz, 64-bit OS.

In this study, the data collected by the inertial sensor from the subjects' right metatarsal is used. Whereas angular velocity, acceleration and magnetic field data are collected from inertial sensors, force data are simultaneously collected from B force platform. An ethics committee report is obtained for the subjects who participate in the study, and then the informed consent form is signed by these subjects. Anthropometric measurements of 11 volunteers who participate in the study are given in Table 2 .

Table 2. The characteristics of the volunteer subjects

\begin{tabular}{cccc}
\hline Subject & Height $(\mathrm{m})$ & Weight $(\mathrm{kg})$ & Age (years) \\
\hline 1-Male & 1.78 & 90 & 20 \\
\hline 2-Male & 1.81 & 83 & 20 \\
\hline 3-Male & 1.80 & 86 & 20 \\
\hline 4-Male & 1.75 & 67 & 26 \\
\hline 5-Female & 1.72 & 60 & 29 \\
\hline 6-Male & 1.90 & 150 & 30 \\
\hline 7-Female & 1.64 & 68 & 34 \\
\hline 8-Male & 1.80 & 77 & 31 \\
\hline 9-Male & 1.80 & 68 & 20 \\
\hline 10-Male & 1.62 & 80 & 31 \\
\hline 11-Female & 1.65 & 55 &
\end{tabular}

7 classifiers such as Decision Tree, Linear Discriminant Analysis (LDA), Gaussian Naïve Bayes, Linear Support Vector Machine (L-SVM), Quadratic Support Vector Machine (Q-SVM), Fine K-Nearest Neighbor (F_KNN), Weighted K- Nearest Neighbor (W-KNN) are used to determine foot movements as Dorsiflexion, Plantarflexion, Inversion, Eversion. 


\subsection{Feature Extraction}

In the first stage, feature extraction, which is a dimension reduction process in which the large data set with many variables is reduced to more manageable groups in order to process.

The data received from the $3 \mathrm{rd}$ sensor connected to the metatarsal is first passed through the feature extraction stage. The features used in this study are sum, mean, standard deviation, covariance, skewness and kurtosis. The statistical features used in the study are given in Equation (1), (2), (3), (4), (5), (6), respectively.

$$
\begin{aligned}
& X=\sum_{i=1}^{n}\left(x_{1}+x_{2}+\cdots+x_{n}\right. \\
& \bar{X}=\frac{X}{n} \\
& S D=\sqrt{\frac{\sum_{i=1}^{n}\left(x_{i}-\bar{X}\right)^{2}}{n}} \\
& \operatorname{cov}(x, y)=\frac{\sum_{i=1}^{n}\left(x_{i}-\bar{X}\right)\left(y_{i}-\bar{Y}\right)}{n-1} \\
& S=\frac{\frac{1}{n} \sum_{i=1}^{n}\left(x_{i}-\bar{X}\right)^{3}}{\left(\sqrt{\frac{1}{n} \sum_{i=1}^{n}\left(x_{i}-\bar{X}\right)^{2}}\right)^{3}} \\
& k=\frac{n \sum_{i=1}^{n}\left(x_{i}-\bar{X}\right)^{4}}{\left(\sqrt{\sum_{i=1}^{n}\left(x_{i}-\bar{X}\right)^{2}}\right)^{2}}
\end{aligned}
$$

\subsection{Classification}

In the study, 5 general classifiers, namely Decision Tree, LDA, Naive Bayes, KNN and SVM, are used. All classification operations are performed using 5-fold cross validation. In classification, observations are 20, predictors are 9 and response classes are 4. Maximum number of splits is 100 and split criterion is Gini's diversity index for Decision Tree. Covariance structure is full for LDA. Distribution name for numeric predictors is Gaussian and distribution name for categorical predictos is MVMN for Naïve Bayes. Kernel functions are linear and quadratic, kernel scale is automatic, box constraint level is 1 and multiclass method is one-vs-one for SVM. Number of neighbors are 1 and 10, distance metric is Euclidean and distance weights are equal and squared inverse for KNN. 


\subsubsection{Decision Tree Classifier}

The decision tree algorithm, one of the most common algorithms in practice, is a predictive model. Its users don't need to be technical, as it is easy to interpret and explain. Decision tree is an algorithm that allows data sets to be split into smaller data sets, and consists of internal nodes that determines the split criteria and leaf nodes where the results are represented (Dev and Eden, 2019; Kotu and Deshpande, 2019; MTech and Rajput, 2019; McClean, 2003).

\subsubsection{Linear Discriminant Analysis}

LDA, an algorithm that assumes that all classes can be separated linearly, is used to distinguish classes by maximizing the distance between two classes. Aiming to project the original data matrix into a lower dimensional area, LDA is one of the most common methods used in dimension reduction. In a two-class dataset, the probabilities for class 1 and class 2 are $p_{1}$ and $p_{2}$, the mean of the classes are $\mu_{1}$ and $\mu_{2}$, respectively. The global mean is $\mu$ and is calculated as in equation (7). Class-scatter matrix $S_{w}$ and scatter matrix between classes $S_{b}$ are calculated using mean values $\mu$. Then, the aim is to find a distinctive plane $J_{L D A}$ which is calculated as in equation (8) to maximize scatter-matrix between classes divided by class-scatter matrix distribution rates, $w$ in that equation is the projection vector (Vaibhaw and Pattnaik, 2020; Witten et al., 2017; Stanimirova et al., 2013; Subasi et al., 2020).

$$
\begin{aligned}
& \mu=p_{1} \times \mu_{1}+p_{2} \times \mu_{2} \\
& J_{L D A}=\frac{w s_{b} w^{T}}{w s_{w} w^{T}}
\end{aligned}
$$

\subsubsection{Naïve Bayes Classifier}

It is a probability-based classifier that assumes that each feature is independent from each other. Since there are no associated features, it performs well even in high-dimensional data sets. Parameters for each term can be learned separately and the processing speed is high (Misra and Li, 2020; Mushtaq, 2017) 


\subsubsection{K-Nearest Neighbor}

$\mathrm{KNN}$, which is frequently used in artificial intelligence and biomedical signal analysis, performs the classification process by comparing the test data with the training data. KNN is applied to an unknown set searches for the nearest $k$ training set in its $n$-dimensional space. The closest $k$ values are calculated using distance measurements. Although it is a simple approach, it has a robust theoretical structure and can outperform much more complex methods (Subasi, 2020; Subasi et al., 2020).

\subsubsection{Support Vector Machines}

SVM, a controlled training algorithm used for classification and regression, has become popular in recent years in neuroimaging analysis, brain disorders and diagnosis of brain diseases such as schizophrenia and Alzheimer's (Pisner, 2020; Malek and Mellouk, 2019).

\subsection{Classification Results}

While calculating the classification accuracies, K-fold cross validation is applied in all studies and the average of 5 trials is taken. In the first stage, the sum is used as a feature for all parameters and the results of 5 trials are recorded. In the second stage, the mean feature is used and again 5 trial results are recorded. In the 3rd stage, mean, standard deviation, skewness and kurtosis are used, and in the 4th stage, the results of 5 trials are recorded using the standard deviation, skewness and covariance. Then, the values in the table are obtained by taking the average of these four results again. These steps are repeated for all classifiers. After obtaining separate results for Linear SVM and Quadratic SVM, a single table is created for SVM by taking their average. Classification accuracies of the raw test data for foot are given in Figure 7, 8, 9, 10, and 11, respectively. Classification accuracy (CA) is given in Equation (9).

$$
C A=\frac{T P+T N}{T P+T N+F P+F N}
$$

Where $T P=$ True Positives, $T N=$ True Negatives, $F P=$ False Positives, and $F N=$ False Negatives. 


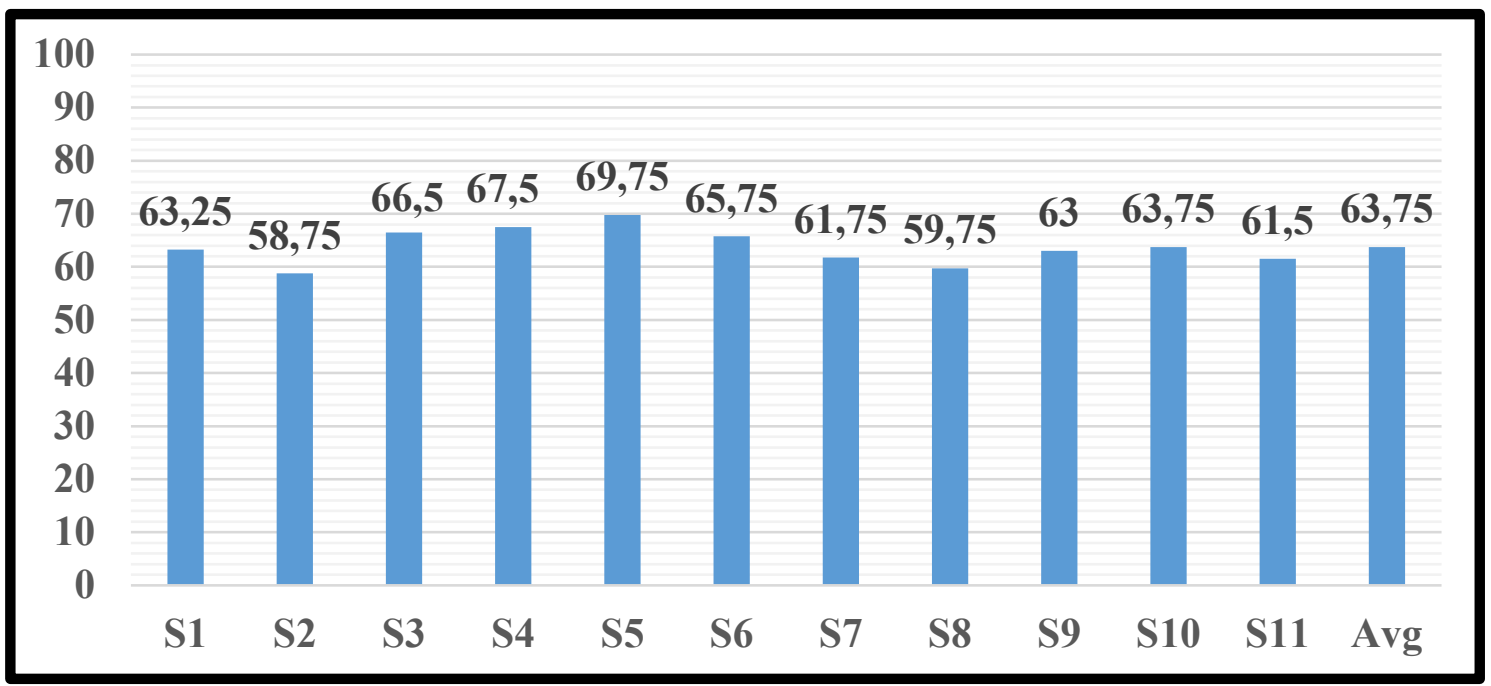

Figure 7. The Decision Tree classification accuracy of the raw test data for foot

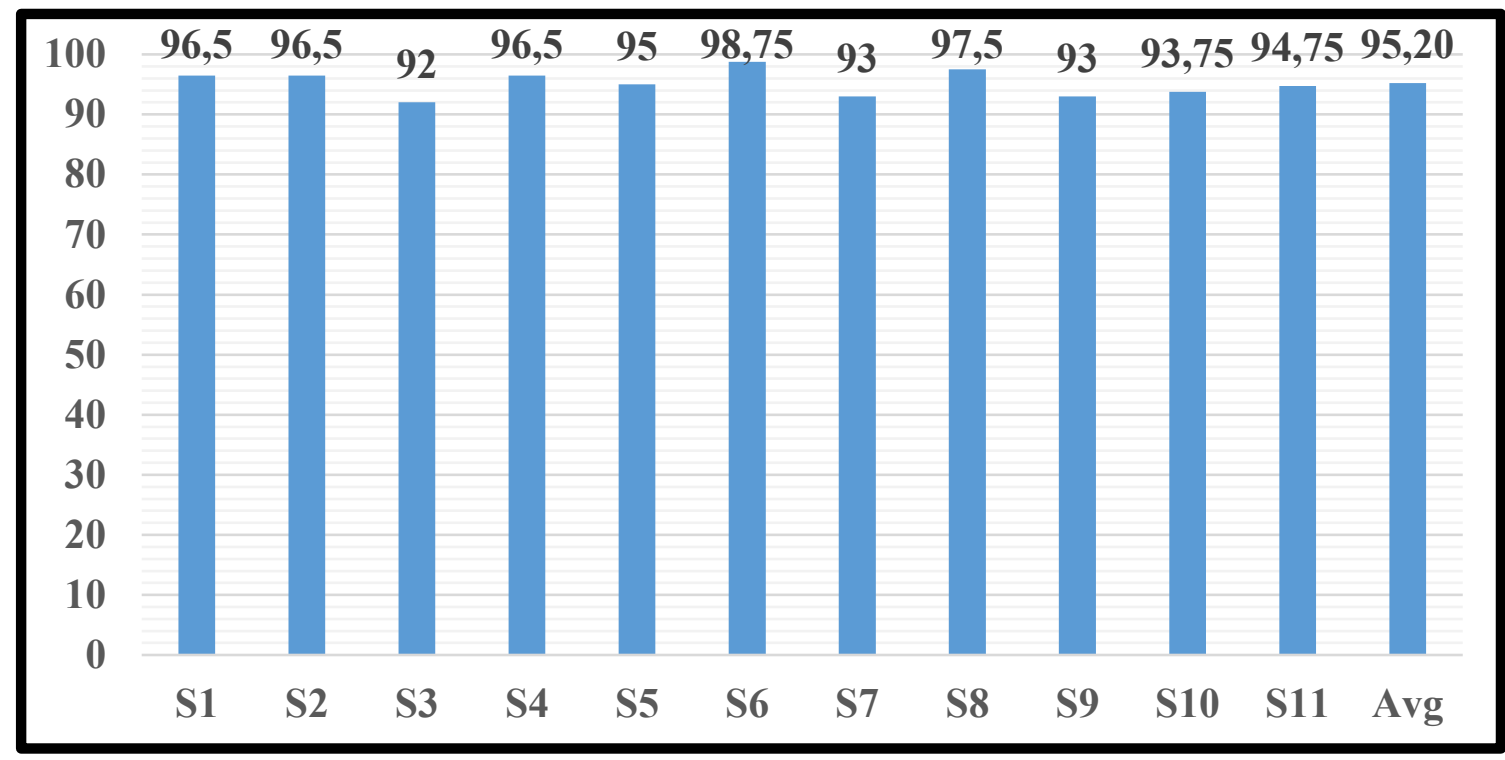

Figure 8. The Linear Discriminant Analysis classification accuracy of the raw test data for foot

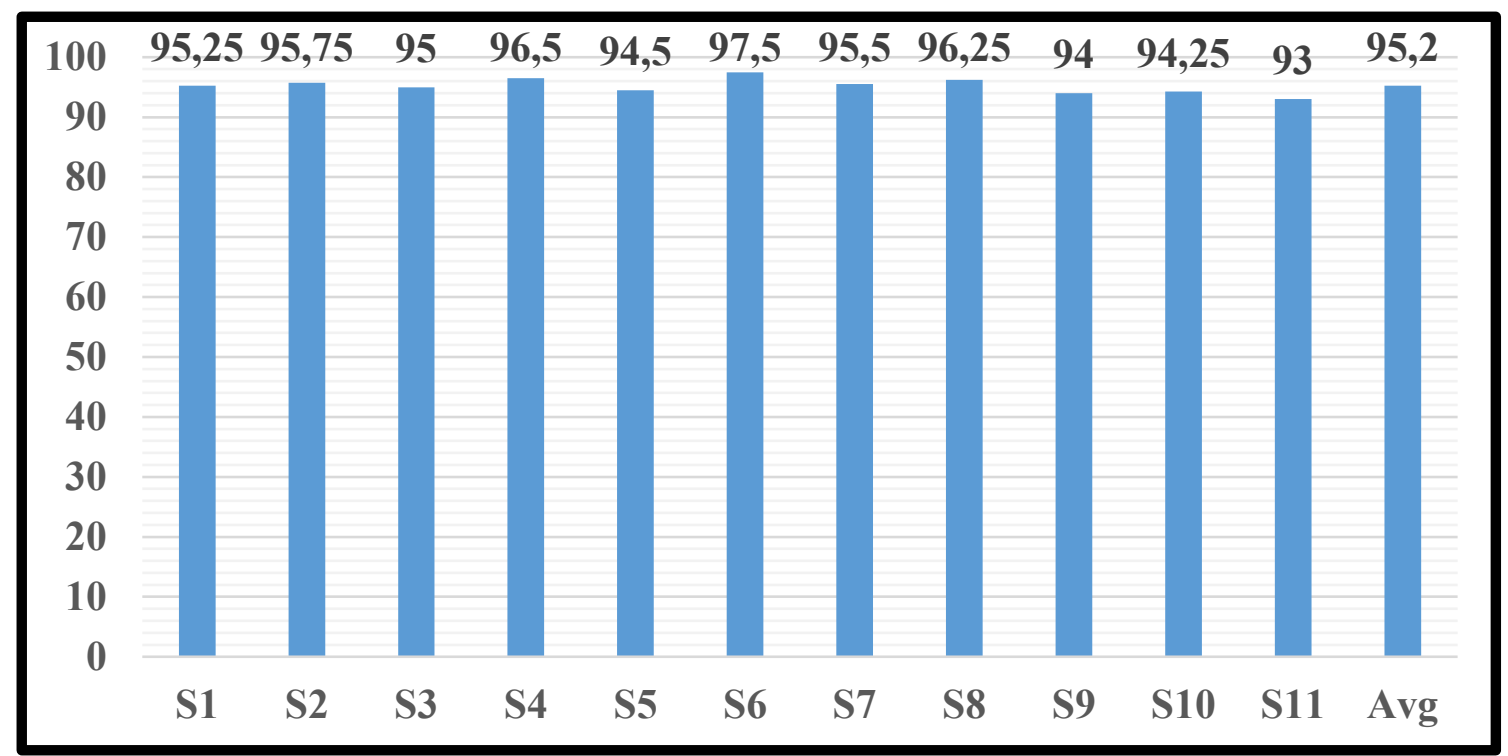

Figure 9. The Gaussian Naïve Bayes classification accuracy of the raw test data for foot 


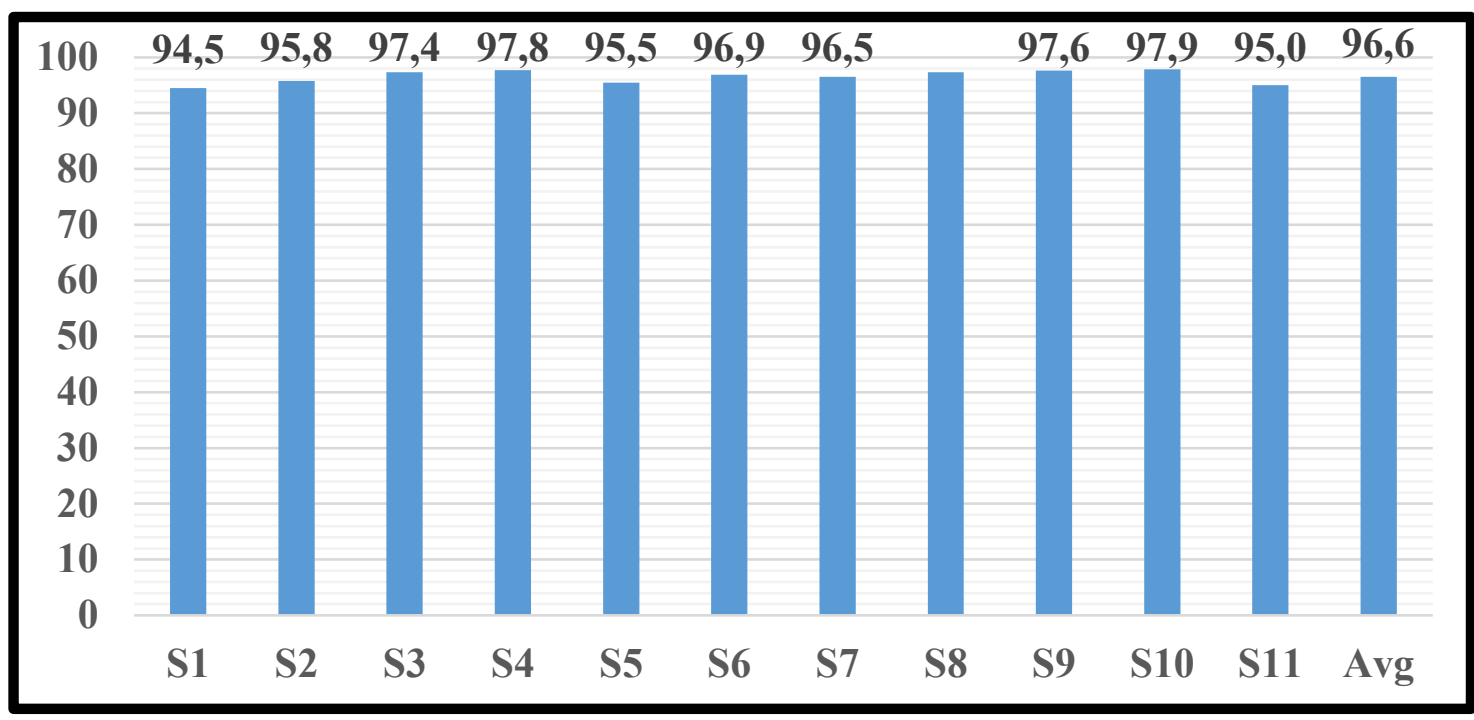

Figure 10. The Support Vector Machine classification accuracy of the raw test data for foot



Figure 11. The K-Nearest Neighbor classification accuracy of the raw test data for foot

When we look at the average values of the results of all subjects in the tables, we see that the highest accuracy is obtained for KNN with $97.2 \%$, and the lowest accuracy is obtained for Decision Trees with $63.75 \%$. It is seen that the accuracy success for LDA, Bayes Classifier and SVM is over 95\%. Looking at the results, it is clear that decision trees are not suitable for human motion classification, while other classifiers have good performance and can be used in motion classification.

\section{Conclusion}

In this study, 9 parameters related to the analysis of foot movements are measured from 11 volunteers with IMU sensors. The raw data obtained from the sensor are passed through the feature extraction and size reduction stages. Classification accuracies are obtained by classifying data with 
reduced size. Classifiers such as Decision Tree Classifier, Linear Discriminant Analysis, Naïve Bayes Classifier, K-Nearest Neighbor and Support Vector Machines are used in classification. When all studies are examined, it is observed that the $\mathrm{KNN}$ algorithm worked better in the classification of foot movements. The methods used are basic artificial intelligence methods. It is aimed to use advanced artificial intelligence methods in future studies. The contribution of this study is that it is a preliminary study on motion detection for use in advanced robotic studies. Perceived movements constitute the reference input of the prosthetic foot control system.

\section{Authors' Contributions}

All authors contributed equally to the study.

\section{Statement of Conflicts of Interest}

There is no conflict of interest between the authors.

\section{Statement of Research and Publication Ethics}

The author declares that this study complies with Research and Publication Ethics.

\section{References}

Dev, V. A., Eden, M.R. (2019). Computer Aided Chemical Engineering, Gradient Boosted Decision Trees for Lithology Classification, Vol. 47, 113-118. doi: 10.1016/ B978-0-12-818597-1.50019-9.

Fleck, J. J., Peters, R. A., Zelik, K. E. (2018). IMU-Based gait analysis in lower limb prosthesis users: comparison of step demarcation algorithms. Gait\&Posture, 64, 30-37. doi: 10.1016/j.gaitpost.2018.05.025

Gao, F., Liu, G., Liang, F., Liao, W. H. (2020). IMU-Based locomotion mode identification for transtibial prosthese, orthoses, and exoskeletons. IEEE Transactions on Neural Systems and Rehabilitation Engineering, Vol. 28, No.6, pp.1334-1343.

Jiang, X., Chu, H. T., Xiao, Z. G., Merhi, L. K., Menon, C. (2016) Ankle Positions Using Force Myography: an Exploratory Investigation, IEEE Healthcare Innovation Point-Of-Care Technologies Conference, 2932. doi: 10.1109/HIC.2016.7797689.

Kotu, V., Deshpande, B. (2019). Data Mining (Second Edition), Chaapter 4: Classification, 65-163. doi: 10.1016/B978-0-12-814761-0.00004-6.

Li, H., Derrode, S., Pieczynski, W. (2019) An adaptive and on-line IMU-based locomotion activity classification using a triplet Markov mode, Neurocomputing, 362, 94-105.

Malek, S., Hui, C., Aziida, N., Cheen, S., Toh, S., Millow, P. (2019). Encyclopedia of Bioinformatics and Computational Biology, Ecosystem monitoring through predictive modeling, Volume 3, 1-8. doi: 10.1016/B978-0-12-809633-8.20060-5. 
McClean, S. I. (2003). Encyclopedia of Physical Science and Technology (Third Edition), Data Mining and Knowledge Discovery, 229-246. doi: 10.1016-B0-12-227410-5/00845-0.

McDermott, M. M., Greenland, P., Liu, K. (2001). Leg symptoms in peripheral arterial disease: associated clinical characteristics and functional impairment. JAMA 2001, 286(13), 1599-606. doi: 10.1001/jama.286.13.1599.

Meffen, A., Pepper, C. J., Sayers, R. D., Gray, L. J. (2020). Epidemiology of major lower limb amputation amputation using routinely collected electronic health data in the UK: a systematic review protocol. BMJ Open 2020, 10(6):e037053. doi:10.1136/bmjopen-2020-037053.

Misra, S., Li, H. (2020). Machine Learning for Subsurface Characterization, Chapter 9- Noninvasive fracture characterization based on the classification on sonic wave travel times, 243-287. doi: 10.1016/B978-012-817736-5.00009-0.

MTech, S. M., Rajput, D. S. (2019). Deep Learning and Parallel Computing Environment for Bioengineering Systems, Nonlinear Decision Tree Regression, 153-164. doi:10.1016/B978-0-12-816718-2.00016-6.

Mushtaq, M. S., Mellouk, A. (2017). Quality of Experience Paradigm in Multimedia Services, 2Methodologies for Subjective Video Streaming QoE Assessment, 27-57. doi: 10.1016/B978-1-78548109-3.500002-3.

Parkka, J., Ermes, M., Korpipaa, P., Peltola, J., Korhonen, I. (2006). Activity classification using realistic data from wearable sensors. IEEE Transaction on Information Technology in Biomedicine, Vol. 10, 119-128.

Pisner, D. A., Schnyer, D. M. (2020). Machine Learning Chapter 6- Support vector machine, 101-121. doi: 10.1016/ B978-0-12-815739-8.00006-7.

Seel, T., Raisch, J., Schauer, T. (2014). IMU-Based Joint Angle Measurement for Gait Analysis. Sensors, 14, 6891-6909. doi: 10.3390/s140406891.

Spoden, M., Nimptsch, U., Mansky, T. (2019). Amputation rates of the lower limb by amputation level observational study using German national hospital discharge data from 2005-2015. BMC Health Services Research, 19(8), 1-9. doi.org/10.1186/s12913-018-3759-5.

Stanimirova, I., Daszyowski, M., Walczak B. (2013). Data Handling in Science and Technology, Chapter 8Robust methods in analysis of multivariate food chemistry data, Volume 28, 315-340. doi:10/1016/B978-0-444-59528-7.00008-9.

Steffen, L. M., Duprez, D. A., Boucher, J. L. et al. (2008) Management of peripheral arterial disease. Diabetes Spectrum, 21:171-7.

Subasi, A. (2020). Practical Machine Learning for Data Analysis Using Python, Chapter 3-Machine learning techniques. 91-202. doi: 10/1016/B978-0-12-821379.7.00003-5.

Subasi, A. (2020). Artificial Intelligence in Precision Health, Chapter 11- Use of artificial intelligence in Alzheimer's disease detection, 257-278. doi:10/1016/B978-0-12-817133-2.00011-2.

Subasi, A., Khateeb, K., Brahimi, T., Sarriete, A. (2020). Innovation in Health Informatics, Chapter-5 Human activity recognition using machine learning methods in a smart healthcare environment, 123-144. doi: 10.1016/B978-0-12-819043-2.00005-8.

Quraishi, M. A., Ishak, A. J., Ahmad, S., Hassan, M. K., Qurishi, M. A., Ghapanchizadeh, H., Alamri, A. (2016) Classification of ankle joint movements based on surface electromyography signals for rehabilitatin robot applications. Medical and Biological Engineering, 55(5). doi: 10.1007/s11517-016$1551-4$.

Vaibhaw, J. S., Pattnaik, P. K. (2020), An Industrial IoT Approach for Pharmaceutical Industry Growth, Chapter 2 Brain- computer interfaces and their applications, 31-54. doi:10.1016/B978-0-12-8213261.00002-4.

Witten, I. H., Frank, E., Hall, M. A., Pal, C. J. (2017) Data Mining (Fourth Edition), Chapter 8-Data transformations, 285-334. doi: 10.1016/B978-0-12-804291-5.00008-8.

Yuliani, S., Saputra M. (2016). Collaboration of Kalman Filter with Complementary Filter to Optimize the Results of Gyroscope and Accelerometer Sensors (In Bahasa Indonesia) in Prosiding Seminar Nasional Rekayasa dan Desain Itenas, 1, 1-6.

Ziegler-Graham, K., MacKenzie, E. J., Ephraim, P. L., Travison, T. G., and Brookmeyer, R. (2008). Estimating the prevalence of limb loss in the United States: 2005 to 2050. Arch. Phys. Med. Rehabil., 89(3), 422-429. doi:10.1016/j.apmr.2007.11.005.

Figure-1: $\quad$ https://www.robotistan.com/sparkfun-9-dof-imu-9-degrees-of-freedom-imu-breakout-lsm9ds1, (Date Accessed: 25 August 2021)

Figure-2: https://cdn.sparkfun.com/assets/learn_tutorials/3/7/3/LSM9DS1_Datasheet.pdf, (Date Accessed:25 August 2021) 